\title{
The Role of Organizational Politics, its Impact on Employee Job Attitude and Creativity: Exploration and Implications for the Higher Education Institutions
}

\author{
Dr. NOOR UN NISA \\ Assistant Professor, Bath Spa University, UAE. \\ Dr. MUHAMMAD NAWAZ \\ (Corresponding Author) \\ Associate Professor, University of Sindh Laar Campus, Badin. \\ Email:mnawaz@usindh.edu.pk \\ Tel: 03337586082 \\ Dr. TAYYABA RAFIQUE MAKHDOOM \\ Assistant Professor, University of Sindh Laar Campus, Badin.
}

\begin{abstract}
The aim of this study to put a light on basics of organizational politics and its negative and positive effects on the employee work related attitudes, more specifically in education sector. In universities administration and faculty are busy in dirty political games rather to pay more attention towards facilitating students for their educational purposes. In universities politics is considered as a dangerous element as the ultimate victim of this politics will be students. Although some studies claimed that politics could be a positive element in organizational growth and development. But, the negative side is heavier than imagination that needs more consideration. A survey has been conducted through a well-structured questionnaire among 100 respondents as well as teaching and administrative staff from different public universities of Sindh Province. The study concluded some significant work related attitudes and outcomes of politics. The main effects of analysis have also revealed that perceptions of politics have significant its impact on employee job attitude and creativity.
\end{abstract}

Keywords: Organizational Politics, Job Attitude, Creativity, Work Related Attitude, Higher Education.

\section{Introduction}

The survival of the organizations in this competitive era is based on innovation, and this can be achieved with the help of creative workforce (Kremer, 2019). Employee creativity is the development of novel and applicable ideas (Duan et al., 2018). The creativity of the employees depends on the culture of the organization, therefore top management of the organizations tend to seek different ways of improving their culture (Taylor, Santiago, \& Hynes, 2019). It is understood by this fact that if the environment is not suitable for the employees then creativity cannot be achieved. Some negative kind of environment that influences employee creativity is organizational politics (Zhang, Sun, Zheng, \& Liu, 2019). This indicates that the presence of organizational politics reduces employee creativity.

Organizational politics have potential to adversely affect job attitude of the employees (Nawaz, Syed, \& Dharejo, 2019). Study (e.g. Ferris, 2018), found negative affect of organizational politics on job attitude. Theoretically, organizational politics influence organizational processes such as promotion, decision- 
making, and rewards, and it also damages the performance and productivity of the employees and organizations. Various empirical evidences also showed similar effects of politics in the organizational context.

The rules of public sector institutions are flexible in Pakistan, as a result individuals take transform these rules according to their will and personal interests (Asrar-u-Haq, 2019). The educational institutes of Pakistan are exposed to politics due to high level of competition. In universities, individuals emanate from various backgrounds; therefore the presence of organizational politics is likely as individuals have to meet their desired objectives without merit (Huang et al, 2019). The individuals employed on universities come across politics in almost every situation, which impacts their performance in terms of creativity and attitude. Thus, the current study has been conducted to examine the role of organizational politics on job attitude and employee creativity in public universities of Sindh, Pakistan.

\section{Research Objectives}

- To examine the impact of Organizational Politics on Job Attitude.

- To assess the impact of Organizational Politics on Employee Creativity.

\section{Literature Review}

\section{Organizational Politics and Job Attitude}

Organizational politics refers to the perceptions of employees about the rewards, organizational recruitment, achievements of goals, allocation of resources, and organizational decision-making (Landells \& Albrecht, 2003). Organizational politics immediately changes the job attitude of the employees (Pillai et al., 2017). Job attitude is defined as the set of evaluations of one's job that involves the feelings, beliefs and attachment to one's job (Vigoda, 2000). These feelings of employees are associated with the culture of the organization (e.g. politics). According to Landells and Albrecht (2019), organizational politics enhances stress level in employees, which adversely affect the job attitude of employees. The employees cannot participate in decision making due to organizational politics, as a result their job attitude changes. A study undertaken by Ramlee et al. (2016) examined the influence of organizational politics on job attitude. The results showed that these constructs had negative relationship. Another recent investigation demonstrated that organizational politics negatively impacts job attitude of the employees as organizational politics increases stress level and reduces job attitude (Dappa et al., 2019). Asrar-ul-Huq (2019) conducted a research on public universities of Pakistan in order to investigate the association between organizational politics and job attitude. In public universities of Pakistan, teachers come across high organizational politics which adversely affect their job attitude; as a result the performance of the students also reduces.

\section{H1: Organizational Politics has a negative relationship with Job Attitude}

\section{Organizational Politics and Employee Creativity}

Employee creativity is getting or gathering of new innovative ideas by the employees that help in improving the quality and overall productivity of the organization (Amabile et al., 1996). There is concrete evidence from the literature that posits the link between organizational politics and employee creativity. In his study Malik et al. (2019) states that if a work environment is such that it is marred by politics and favouritism, then an employee might adopt a defensive approach when it comes to developing and sharing ideas. Baas et al. (2018) concluded that the defensive behaviour of the employees in response to a politically charged organizational climate leads to a reduction in employee creativity. According to Cerne et al. (2014) in a political organizational environment the employee feels that being creative would prove to be too risky so consequently he/she will stop being creative. Since, organizational politics is characterized 
by favouritism and behaviours that are self-serving; it leads to the development of destructive work-related attitudes amongst the employees, one of which is a reduction in employee creativity (Bedi \& Schat, 2013). In a study conducted by Aryee et al., (2009) the perception of organizational politics was found to be negatively linked with creativity. Furthermore, Malik et al., (2018) concluded in their study that organizational politics was a negative predictor of employee creativity in public universities of Pakistan.

H2: Organizational Politics has a negative relationship with Employee Creativity

\section{Theoretical Framework}

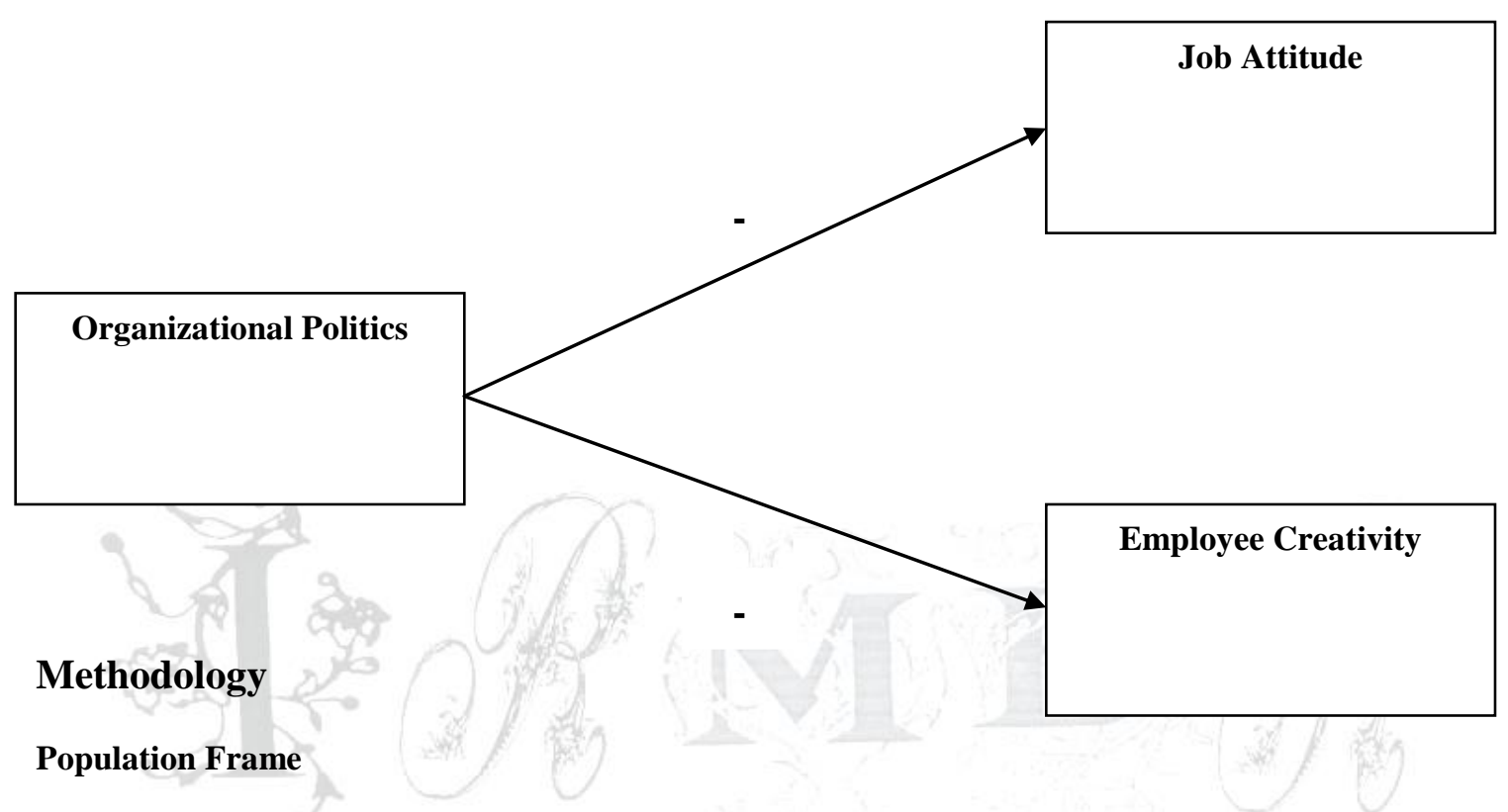

The population for the current study are the teachers and administrative staff working in public universities of Sindh, Pakistan.

\section{Sample Selection/Sample Size}

A sample was extracted from the population that comprised of the responses of the teachers and administrative staff employed in the public universities of Sindh. A non- probability convenience sampling technique was used for this research. This technique has been considered due to time and cost constraints. Around 200 questionnaires were distributed to employees working in three public universities, but received 125, among those 100 were usable for further analysis. According to the sample theory proposed by Roscoe (1975), However, some statistical experts suggest a data range between 5-10 times the number of items used in the scale (Hair, Black, Babin and Anderson, 2010). Hence, the sample size of 100 was taken for the present study.

\section{Unit of Analysis}

The unit of analysis for the purpose of this study was individual as it was focused on teachers and administrative staff employed in the public universities of Sindh. Around 28 private universities and 18 public hec recognized universities are established in the Sindh. For conducting this study, data has been collected from three public universities in jamshoro, Sindh including University of Sindh, Mehran University and Liaquat Medical University were selected to collect data. 


\section{Type of Study/Time Horizon}

The research study was quantitative because a quantitative approach was utilized in order to obtain data from the respondents through questionnaires. The study was cross-sectional in nature as the data was collected at one point of time only. Given the time constraints, a cross-sectional approach helped us to obtain data on many variables in less amount of time.

\section{Instrument Development/Selection}

The questionnaires consisting of the items against each variable under study were adopted. A 5-point Likert scale, (Likert, 1960) was used.

Table 1: Measurement of Scales

\begin{tabular}{llc}
\hline Variable & Items & Source \\
\hline Organizational Politics & 07 & Maslyn, John, and Donald (1998) \\
Job Attitude & 10 & Flannery, Resnick, Galik, Lipscomb, and McPhaul \\
Employee Creativity & 07 & Gong, Yaping, Jia-Chi Huang, and Jing-Lih Farh
\end{tabular}

(2009)

\section{Data Collection Procedure}

The data was collected through a questionnaire that was adopted containing the items against a Likert scale for the variables namely, Organizational Politics, Job Attitude, and Employee creativity, Questionnaires were sent through Google form due to the prevalence of Covid-19 pandemic. Simple random technique was used to access participant online on different social media platforms e.g. Facebook, LinkedIn, Instagram etc.

\section{Data Analysis Techniques}

The data collected with the help of questionnaires was arranged and analysed using SPSS software. Various tests were conducted including: Demographics, Regression, Correlation, Reliability, and Descriptive Statistics to test the hypothesis. Before conducting above mention analysis, screening of data were performed by conducting normality and outlier test and resulting piloted graphs in the SPSS.

\section{Data Analysis}

\section{Demographic Analysis}

The demographic analysis shown in the table given above depicts that 45 participants were aged between 20-30 years, 41 were aged between 31-40 years, 6 belonged to the age group of 41-50 years whereas, 8 were above 50 years of age. The gender distribution shows that males constituted $61 \%$ of the sample size whereas, $39 \%$ of the respondents were females. It can also be observed that 40 participants possessed a bachelor's degree, 35 had a master's qualification whereas, 25 participants possessed some other diploma education. The income distribution shows that 47 participants had an income of less than Rs.50,000. 28 
respondents had an income ranging between Rs.50,000 to Rs.100,000, 16 individuals had an income of Rs.100,000 to Rs.200,000, 6 had an income ranging between Rs,200,000 to Rs,300,000 whereas only 3 participants had an income of more than Rs.300,000.

Table 2: Demographic Information

\begin{tabular}{|c|c|c|c|}
\hline Fact & Description & Frequency & Valid \% \\
\hline \multirow[t]{4}{*}{ Age } & $20-30$ years & 45 & 45 \\
\hline & $31-40$ years & 41 & 41 \\
\hline & $41-50$ years & 6 & 6 \\
\hline & Above 50 years & 8 & 8 \\
\hline \multirow[t]{2}{*}{ Gender } & Male & 61 & 61 \\
\hline & Female & 39 & 39 \\
\hline \multirow[t]{3}{*}{ Qualification } & Bachelors & 40 & 40 \\
\hline & Masters & 35 & 35 \\
\hline & Other Degree/Diploma & 25 & 25 \\
\hline \multirow[t]{5}{*}{ Income } & Less than Rs. 50,000 & 47 & 47 \\
\hline & Rs. 50,000 - Rs. 100,000 & 28 & 28 \\
\hline & Rs. 100,000 - Rs. 200,000 & 16 & 16 \\
\hline & Rs. 200,000 - Rs. 300,000 & 6 & 6 \\
\hline & Above Rs. 300,000 & 3 & 3 \\
\hline
\end{tabular}

\section{Reliability Analysis}

Table 1: Reliability Analysis

\begin{tabular}{lcc}
\hline Variables & No. of Items & Cronbach Alpha ( $\boldsymbol{\alpha})$ \\
\hline Organizational Politics & 07 & .806 \\
Job Attitude & 10 & .898 \\
Employee Creativity & 07 & .885 \\
\hline
\end{tabular}


The table given above depicts the reliability of the instruments that were adopted to measure the variables of the study. It can be seen that organizational politics had 07 items with a reliability of 0.806 , job attitude had 10 items with a Cronbach Alpha of 0.898 whereas, employee creativity had 07 items with an alpha value of 0.885 . Many researchers have suggested a Cronbach Alpha value of greater than 0.60 to be acceptable. It can be seen that all Cronbach Alpha values are greater than 0.60 which means that all the research instruments are highly reliable.

\section{Descriptive Statistics}

Table 2: Descriptive Statistics

\begin{tabular}{ccccc}
\hline & Mean & $\begin{array}{c}\text { Std. } \\
\text { Deviation }\end{array}$ & Skewness & Kurtosis \\
\hline OP & 3.5871 & .58388 & -.090 & 1.155 \\
JA & 3.8100 & .55659 & -.133 & .265 \\
EC & 3.9857 & .63904 & -.382 & .100 \\
\hline
\end{tabular}

According to the descriptive statistics, the mean values for organizational politics (OP), job attitude (JA) and employee creativity (EC) are 3.5871, 3.8100, and 3.9857 respectively. The values of standard deviation are within the acceptable threshold limits which means that the data is evenly dispersed around the mean. The values of skewness and kurtosis are also within the acceptable threshold limits of -1 to +1 and -3 to +3 respectively. Hence, it can be deduced that the data is normal and thus perfect for carrying out further statistical tests.

\section{Correlation Analysis}

\begin{tabular}{|c|c|c|c|c|}
\hline & & OP & JA & EC \\
\hline \multirow{3}{*}{ OP } & Pearson Correlation & 1 & & \\
\hline & Sig. (2-tailed) & & & \\
\hline & $\mathrm{N}$ & 100 & & \\
\hline \multirow{3}{*}{ JA } & Pearson Correlation & $-.299^{88}$ & 1 & \\
\hline & Sig. (2-tailed) & .002 & & \\
\hline & $\mathrm{N}$ & 100 & 100 & \\
\hline \multirow{3}{*}{$\mathrm{EC}$} & Pearson Correlation & $-.344^{88}$ & $.537^{* 8}$ & 1 \\
\hline & Sig. (2-tailed) & .000 & .000 & \\
\hline & $\mathrm{N}$ & 100 & 100 & 100 \\
\hline
\end{tabular}

The table shown above depicts the results of the correlation analysis between organizational politics (OP), job attitude (JA), and employee creativity (EC). It can be seen that organizational politics and job attitude are significantly and negatively correlated with each other. A significant and negatively correlation can also be observed between organizational politics and employee creativity. However, the magnitude of these correlations is weak to moderate (i.e., less than 0.50 ). 


\section{Regression Analysis}

\section{Regression between Organizational Politics and Job Attitude}

Table 4: Regression Analysis for Organizational Politics and Job Attitude

\begin{tabular}{ccccccc}
\multicolumn{7}{c}{ Coefficients $^{\mathbf{a}}$} \\
\hline \multirow{2}{*}{ Model } & \multicolumn{2}{c}{$\begin{array}{c}\text { Unstandardized } \\
\text { Coefficients }\end{array}$} & $\begin{array}{c}\text { Standardized } \\
\text { Coefficients }\end{array}$ & t & Sig. \\
\cline { 3 - 6 } & & B & Std. Error & Beta & & \\
\cline { 2 - 5 } 1 & (Constant) & 2.787 & .334 & & 8.346 & .000 \\
& OP & -.285 & .092 & -.299 & -3.104 & .002 \\
\hline
\end{tabular}

a. Dependent Variable: JA

\section{Model Summary}

\begin{tabular}{cc}
\hline R & .299 \\
R Square & .090 \\
Adjusted R Square & .080 \\
F-value & 9.637 \\
Sig. & .002 \\
\hline
\end{tabular}

The results of the regression analysis between organizational politics and job attitude are significant as indicated by the significance value which is less than 0.05 . The beta value depicts that an increase of 1 -unit in organizational politics will lead to a decrease of 0.299 units in job attitude. Hence it can be concluded that organizational politics and job attitude are negatively related with each other.

\section{Regression between Organizational Politics and Employee Creativity}

Table 5: Regression for Organizational Politics and Employee Creativity

\begin{tabular}{|c|c|c|c|c|c|c|}
\hline \multicolumn{7}{|c|}{ Coefficients ${ }^{\mathbf{a}}$} \\
\hline \multirow[t]{2}{*}{ Model } & & Unstand & ardized & Standardized & $\mathrm{t}$ & Sig. \\
\hline & & B & Std. Error & Beta & & \\
\hline \multirow{2}{*}{1} & (Constant) & 2.634 & .377 & & 6.984 & .000 \\
\hline & OP & -.377 & .104 & -.344 & -3.630 & .000 \\
\hline
\end{tabular}

Model Summary

\begin{tabular}{cc}
\hline R & .344 \\
R Square & .119 \\
Adjusted R Square & .110 \\
F-value & 13.175 \\
Sig. & .000 \\
\hline
\end{tabular}


The results of the regression analysis between organizational politics and employee creativity are also significant as indicated by the significance value which is less than 0.05 . The beta value depicts that an increase of 1-unit in organizational politics will lead to a decrease of 0.344 units in employee creativity. Hence it can be deduced that organizational politics and employee creativity are negatively related with each other.

\section{Findings, Conclusion And Recommendations}

\section{Findings}

On the basis of the results of the data analysis, the current study presents the following findings:

- There is a negatively relationship between organizational politics and employee job attitude.

- A negative relationship exists between organizational politics and employee creativity.

These findings are consistent with the findings of the previous studies mentioned in the literature. For instance, the findings of the current study support the findings of Dappa et al. (2019) and Israr ul Haq (2019) which also suggested a negative association between organizational politics and job attitude. Moreover, the findings of this study are also in line with the findings of Bass et al. (2018) and Malik et al. (2019) which also posited a negative relationship between organizational politics and employee creativity.

\section{Conclusion}

The present study concludes that organizational politics is a major antecedent that adversely impacts the employees' job attitude and creativity. Therefore, it becomes imperative for the organizations to undertake measure that are aimed at mitigating organizational politics and ensuring fair, equitable, and transparent treatment for all employees and stakeholders. Accountability mechanisms should be devised and implemented in order to minimize the organizational political climate in order to inculcate a positive job attitude and promote a workplace culture that encourages employee creativity.

\section{Limitations and Recommendations for Future Studies}

There were certain limitations associated with this study such as limited scope and sample size. Therefore, the results may not be generalizable. Therefore, it is recommended that future studies should increase the sample size to improve generalizability of the results. Advanced research designs and statistical techniques should be adopted to generate more accurate and reliable results. Moreover, new variables such as job performance, productivity, and employee mental well-being can be studied in order to comprehensively assess the negative effects of organizational politics.

\section{References}

Amabile, T. M. (1983). The Case for a Social Psychology of Creativity. The Social Psychology of Creativity, 3-15. doi:10.1007/978-1-4612-5533-8_

Aryee, S., Zhou, Q., Sun, L.-Y., \& Lo, S. (2009). Perceptions of politics, intrinsic motivation and creative performance: evidence from the service sector. Academy of Management Proceedings, 2009(1), 1-6. doi:10.5465/ambpp.2009.44243022

Asrar-ul-Haq, M., Ali, H. Y., Anwar, S., Iqbal, A., Iqbal, M. B., Suleman, N., ... Haris-ul-Mahasbi, M. (2019). Impact of organizational politics on employee work outcomes in higher education institutions of Pakistan. South Asian Journal of Business Studies, 8(2), 185-200. doi:10.1108/sajbs-07-2018-0086

Baas, M., De Dreu, C. K., \& Nijstad, B. A. (2008). A meta-analysis of 25 years of mood-creativity research: Hedonic tone, activation, or regulatory focus?. Psychological bulletin, 134(6), 779. 
Bedi, A., \& Schat, A. C. H. (2013). Perceptions of organizational politics: A meta-analysis of its attitudinal, health, and behavioural consequences. Canadian Psychology/Psychologie Canadienne, 54(4), 246259. doi:10.1037/a0034549

Černe, M., Nerstad, C. G. L., Dysvik, A., \& Škerlavaj, M. (2014). What Goes Around Comes Around: Knowledge Hiding, Perceived Motivational Climate, and Creativity. Academy of Management Journal, 57(1), 172-192. doi:10.5465/amj.2012.0122

Dappa, K., Bhatti, F., \& Aljarah, A. (2019). A study on the effect of transformational leadership on job satisfaction: The role of gender, perceived organizational politics and perceived organizational commitment. Management Science Letters, 9(6), 823-834.

Duan, S., Liu, Z., \& Che, H. (2018). Mediating influences of ethical leadership on employee creativity. Social Behavior and Personality: An International Journal, 46(2), 323-337. doi:10.2224/sbp.6160

Ferris, G. R., Fedor, D. B., \& King, T. R. (1994). A political conceptualization of managerial behavior. Human Resource Management Review, 4(1), 1-34. doi:10.1016/1053-4822(94)90002-7

Flannery, K., Resnick, B., Galik, E., Lipscomb, J., \& McPhaul, K. (2012). Reliability and Validity Assessment of the Job Attitude Scale. Geriatric Nursing, 33(6), 465-472. doi:10.1016/j.gerinurse.2012.05.002

Huang, B. E., Sardeshmukh, S., Benson, J., \& Zhu, Y. (2019). The Role of Creativity and High Performance Work Systems in Public Sector Performance. Academy of Management Proceedings, 2019(1), 11108. doi:10.5465/ambpp.2019.175

Kremer, H., Villamor, I., \& Aguinis, H. (2019). Innovation leadership: Best-practice recommendations for promoting employee creativity, voice, and knowledge sharing. Business Horizons, 62(1), 65-74. doi:10.1016/j.bushor.2018.08.010

landells, E. M., \& Albrecht, S. L. (2019). Perceived Organizational Politics, Engagement, and Stress: The Mediating Influence of Meaningful Work. Frontiers in Psychology, 10. doi:10.3389/fpsyg.2019.01612

Malik, O. F., Shahzad, A., Raziq, M. M., Khan, M. M., Yusaf, S., \& Khan, A. (2019). Perceptions of organizational politics, knowledge hiding, and employee creativity: The moderating role of professional commitment. Personality and Individual Differences, 142, 232-237. doi:10.1016/j.paid.2018.05.005

Shahani, N. un N., Nawaz, M., Syed, A., \& Dharejo, N. (2019). Two Facets of Organizational Politics, the Constructive and Destructive Role of Organizational Politics on Employee Work Related Attitudes: A Theoretical Study. Annals of Contemporary Developments in Management \& HR, 1(1), 15-22. doi:10.33166/acdmhr.2019.01.003

Pillai, K. G., Hodgkinson, G. P., Kalyanaram, G., \& Nair, S. R. (2015). The Negative Effects of Social Capital in Organizations: A Review and Extension. International Journal of Management Reviews, 19(1), 97-124. doi:10.1111/ijmr.12085

Ramlee, N., Osman, A., Salahudin, S. N., Yeng, S. K., Ling, S. C., \& Safizal, M. (2016). The Influence of Religiosity, Stress and Job Attitude towards Organizational Behavior: Evidence from Public Universities in Malaysia. Procedia Economics and Finance, 35, 563-573. doi:10.1016/s22125671(16)00069-1

Taylor, A., Santiago, F., \& Hynes, R. (2019). Relationships Among Leadership, Organizational Culture, and Support for Innovation. Effective and Creative Leadership in Diverse Workforces, 11-42. doi:10.1007/978-3-030-02348-5_2

Vigoda, E. (2000). Organizational Politics, Job Attitudes, and Work Outcomes: Exploration and Implications for the Public Sector. Journal of Vocational Behavior, 57(3), 326-347. doi:10.1006/jvbe.1999.1742

Zhang, Q., Sun, S., Zheng, X., \& Liu, W. (2019). The Role of Cynicism and Personal Traits in the Organizational Political Climate and Sustainable Creativity. Sustainability, 11(1), 257. doi:10.3390/su11010257 